\title{
THE HISTORICALLY CHANGING NOTION OF (FEMALE BODILY) PROPORTION AND ITS RELEVANCE TO LITERATURE
}

\author{
TAKAYUKI YOKOTA-MURAKAMI* \\ The Graduate School of Language and Culture, Osaka University, Japan
}

\begin{abstract}
Futabatei Shimei (1864-1909) was an early modern Japanese novelist, translator, and critic. He wrote what is now generally conceived of as the first Japanese 'modern' novel, Drifting Clouds (1887-89). He translated works by Turgenev, Leo Tolstoy, Garshin, Gorky, and others. He also published a number of critical essays, treatises on literary theory, political papers, and so forth. His early translation of Turgenev's short stories: Aibiki (Rendevous, 1888) and Meguriai (Three Trysts, 1889) were extremely influential on the contemporary literati, who were amazed at the fresh, poetic prose used in stark contrast to the traditional Japanese fiction in the pre-Reformation period. These translations, seen in the light of the present-day readers, were unique in what we might term today 'foreignizing translation'. Lawrence Venuti in Invisibility of the Translator argues that the ideal of (English) translation has been to conceal itself as a translation, i.e. to present itself as an original text (chap I and passim). In that sense, Futabatei's translations, scandalously presenting itself as a translation, that is to say, as an alien text, is extremely 'foreignizing'.
\end{abstract}

KEYWORDS: Futabei, translation, modern novel, foreignizing

\section{Introduction}

For one thing, Futabatei, with the help of ruby, often supplied original Russian words in translation, making it clear that the text was a translation. Secondly, the translated texts are scattered with a number of explicatory, at times quite lengthy, notes. In Rendevous Futabatei, the translator, often uses the original Russian words or their English renderings in place of Japanese translations (frequently accompanied by notes). Ruby, or gloss, is a unique textual device in Japanese, in which explicatory phrases or texts are attached to the main text to the right (traditionally, Japanese texts are written and printed from top to bottom). Sometimes it is a pronunciation guide (Chinese hieroglyphs used in Japanese may have a few different

* TAKAYUKI YOKOTA-MURAKAMI (PhD 1994, Princeton University) is Professor of Comparative Literature at The Graduate School of Language and Culture, Osaka University, Japan. E-mail: yokotamurakami@fullbrightmail.org. 
pronunciations, out of which it is often difficult to determine the right one). Sometimes it gives translation. For instance, an early modern Japanese writer often printed the word ren'ai 恋愛 (love) with a gloss rabu, which was a Japanese transliteration for the English word 'love' in order to emphasize that he/she was talking about the Western progressive notion of 'love'. For instance, he writes paparotoniku for Russian popolotnik, adding a note in parentheses that it is 'a kind of bracken' (Futabei 1971: 82). He renders biriuza into 'turquoise' (noting that it is a 'kind of jewelry') and nezabytka (forget-me-not) into 'myosotis' (noting that it is 'a name of a herb', Futabei 1971: 83). In Three Trysts such a method of translation is carried further to the hysterical extreme. Futabatei transliterates chernysh (sandpiper) as chorunuishi and notes that: 'This must be a name of a bird, but I haven't been able to figure out a proper translation in Japanese' (Futabei 1971: 94). He repeatedly adds apologetic explanatory notes, sometimes gloomily confessing that: 'This is a free translation; Dialogues, in contrast to narration, are hard to be translated literally' (Futabei 1971: 91), at others, that: 'This is a translation for the original word nezhilos', but it does not perfectly convey the meaning of the original. A Russian-English dictionary renders it into 'tsu, pamupaa, wan, serufu (to pamper oneself), which does not appear to be a perfect equivalent', either (Futabei 1971: 89). These textual 'noises' emphasize that the original text is, in the last instance, incomprehensible and inexplicable. In such a way, Futabatei Shimei, the translator, presented also the rendered texts as completely alien. This is a case of extreme 'foreignizing'.

\section{Futabei's Foreignizing Practice}

In one of those foreignizing translations Futabatei renders the Russian adjective stroinyi as ada-na with a gloss 'well-formed' in English. The word appears in Three Trysts where the hero for the first time spots a mysterious young, beautiful woman whom he was to meet three times at different locations (Futabei 1971: 90). (Incidentally, Futabatei re-translates Three Trysts in 1896. In the new version he retains the translation of ada-na for stroinyi, but removes the notes 'well-formed'. Thus, Futabatei slowly shifted towards a more 'domesticating' translation.)

Now, what does the adjective stroinyi mean? Contemporary RussianEnglish dictionaries translate stroinyi as 'well-proportioned' (for instance, The Oxford Russian-English Dictionary, 1980).

We will return to the issue of what is the exact meaning-content of a 'good proportion' later. Apart from that, the Japanese translation of ada-na instantly sounds weird. The term $a d a$ is an ancient, classic term, already in common circulation early in the 10th century (-na in ada-na is an adjective ending). The Shogakkan kokugo daijiten (The Great Shogakkan Dictionary of 
Japanese) gives a definition of taoyakade utsukushii, nayoyakade namamekashii (graceful and beautiful; slender and charming). The Dictionary, however, adds the second definition of iroppoi (sexy), relating it to the late Shogunate aesthetic/sexual ideal of $i k i$.

The association of ada-na via the demimondian Japanese notion of $i k i$ is, naturally, quite inappropriate for the pure, romantic world of Turgenev, where the hero senses a fantastic longing for an enigmatic woman with a celestial beauty.

$I k i$ is both a code of conduct and a principle of aesthetics widely recognized within the pleasure quarters and their vicinities in the Tokugawa period (the Shogunate of 1603-1868). It highlighted coolness, playfulness, and sophisticated aestheticism. Applied to feminine beauty, it referred to good, well-calculated taste in fashion, toilet, manners, behavior, and so on. In that respect, this Japanese idea concerned mental, rather than, bodily features of women (it is true, though, that, as a concept arising from the pleasure quarters, it did convey the sensual connotations [which was not necessarily contradictory to its referring to the standards of refinement]). It did occasionally pertain to the way women made up or dressed themselves. But what mattered most was the sophistication, consideration, and connoisseurship that they expressed through makeup and dress.

The ideal was typically represented by high-ranking courtesans in the urban pleasure quarters. The Japanese word ada-na that Futabatei used as a translation for Russian stroinyi came (rather unexpectedly) out of such traditionally Japanese conceptions about female beauty. At any rate, sexual (erotic) attraction (realized through cultural refinement) was at issue. This, certainly, must not have been the connotation that Turgenev was trying to convey. Futabatei's translation of stroinyi into adana was, obviously, a mistranslation. What caused the translator to make such an 'error'?

When Futabatei translated Turgenev's short stories while he was still studying at the Tokyo School of Foreign Languages, he had access to reference materials stacked at the library of the School. Some of the references that he could have used were: Reif's quadrilingual dictionary, Dal's Comprehensive Dictionary, and Furukawa's Russo-Japanese dictionary. The dictionary was edited and published by a well-known writerethnographer Vladimir Dal' in 1863-68). With its rich insight into Russian culture, it has remained the standard reference material for literati and intellectuals in general. I could only consult the eighth edition (reprint) of 1934. The books in Russian formerly stacked in the library of the Tokyo School of Foreign Languages are now constitute the special collection 'Books Owned by the former Tokyo School of Foreign Languages' in the library of Hitotsubashi University (formerly, the Tokyo School of Commerce, to which the Tokyo School of Foreign Languages was annexed 
in 1885). According to this catalogue, Futabatei could have consulted the 1866 edition.

Futabatei, as I have shown above, abundantly used English words as supplementary notes to the translation. Consequently, it is quite obvious that the translator consulted Russian-English dictionaries constantly. F. Reif's New Parallel Dictional of Russian, French, German, and English Dictionary of 1879 translates stroinyi as 'well-formed, fine-shaped' (just like Futabatei did in his translation). To be sure, A. Aleksandrov's Complete Russian-English Dictionary was the standard Russian-English dictionary of the period and the library of the Tokyo School stacked this dictionary as well. However, upon textual analyses and comparison between the original and Futabatei's translation, we have determined that Futabatei was mostly using Reif's dictionary (cf. Yokota-Murakami 2016, II, sec. 3). Reif's Dictionary is found in the above-cited catalogue of the Collection, published by the library of Hitotsubashi University. (We have consulted the third edition of 1866 edition of it, whereas the fourth edition of 1875 was stacked at the library of the Tokyo School of Foreign Languages.) The Russian dictionary of Dal' defines stroinyi as 'body parts being arranged in a certain order.' This is, perhaps, a more baffling definition than the English translation of 'wellformed' as it does not give any idea what that 'certain' order is, while not even describing it (it is unclear whether this order is good or bad). Finally, the representative Russian-Japanese dictionary of the period Rowa jii gives the translation of stroinyi as seisei taru, seizen taru (neatly, regularly). (Rowa jii was edited by Tsuneichiro Furukawa, the renowned philologist and the mentor of Futabatei at the Tokyo School of Foreign Languages. Therefore, it stands to reason to assume that Futabatei consulted this dictionary. We have been, however, able to take a look at the eighth edition of it. (Which edition Futabatei had access to in the library of the Tokyo School of Foreign Languages is not known.) Nonetheless, as the explanation of the eighth edition is not particularly helpful, it is dubious if Futabatei found the translation in the earlier edition which he consulted useful.) As an example referring to the physical aspect of the word, it gives stroinyi stan and translates it as 'seizen taru shintai (well-ordered body)'. Once again it does not help as it lacks the explanation as to what is meant by a good order of a body. Neither of them (Russian, Russo-English, and Russo-Japanese dictionaries) gives a clear image of a female bodily beauty that is implied in the word stroinyi.

So what was the translator to do when the dictionaries did not offer help?Apparently, when he read the word stroinyi in the original text and found its meaning as 'having a good proportion' both in Russian dictionaries and in bilingual dictionaries, Futabatei, the translator, had no clue as to what was meant by 'good proportion'. In contrast to the 
contemporary flood of visual images via films, television, internet, etc., readers of literatures in foreign languages rarely had access to them. Information on the Western civilization was purely discursive; that is to say, through the printed media. And if available reference materials chose not to give a fuller explanation of 'good proportion' (which was, probably, obvious to the members of the given cultures), Futabatei had no idea what it really was. Then, all he could do was to consult the cultural standard of his own society. What exactly was a good feminine form? To begin with, for the Japanese of the seventeenth to the mid-19th century, beautiful women were necessarily found in the pleasure quarters. (On the association of female beauty with women of the demi-monde, see Yokota-Murakami 2011: 91110.) And they are distinguished by their $i k i$ style, that is, by their refined, well-calculated appearance (dress, makeup, and so on). They were seldom applauded by their physical proportion: a woman with a gorgeous body would have been a total fiasco if she had been dressed with a poor taste.

Secondly, if one, all the same, paid attention to the crude physical figure as it was, it was not a glamorous body that was evaluated; it was a willowy, slender proportion. This ideal of feminine proportion is clearly expressed in the ukiyo-e (wood-printings) of Harunobu Suzuki (1725-70), master of female figures, mostly in demimonde. In the Tokugawa period (Shogunate), an object of love (and/or sex; Tokugawa Japanese seldom made distinction between the two) was normally sought in the pleasure quarters. Hence, the female beauty (spiritual and/or physical; once again, the Tokugawa Japanese did not make serious conscious distinction between the two) that attracted men was sought there. Slender, willowy (beautiful) figure was, thus, mostly attributed to women in the pleasure quartersBeautiful slender women were invariable topic for Suzuki. Suzuki's fetishization of a slim body (mostly, of courtesans and geishas) determined and represented the sexual atmosphere of the period. Otaku (the Japanese cyber nerds)'s penchant for an immature (hence, poorly developed) female body is well documented and discussed. We will return to this issue below. 


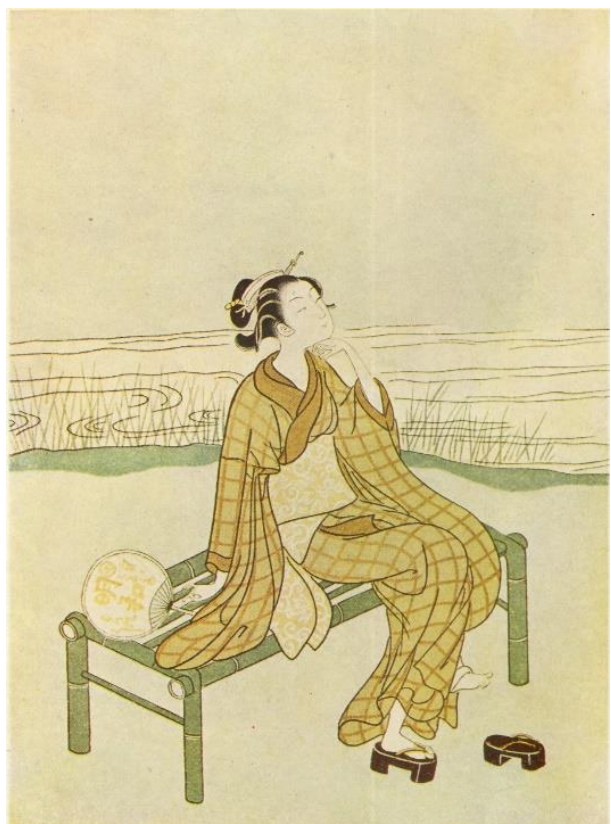

Fig. 1. Harunobu Suzuki, 'A Woman Cooling Down Herself on the Bench'.

Whether Suzuki was the initiator of this fad for a slender woman is not clear to the author. This theme would require a far more extensive historical and philological research. One is tempted to hypothesize that such a penchant had a very long pre-history. Reading, for example, The Tale of Genji, one is convinced that the ideal was the same in the 11 th century (most of the beauties in the Tale are skinny and fragile). This tempts one to stipulate that the ideal of feminine slenderness has always been the tradition in Japan, but I will refrain from such generalization. This hypothesis needs thorough verification. It is worth, however, to point to the source to this aesthetic judgment that may be sought in the Chinese tradition. Historically speaking, the fetish for slenderness was, probably, influence by the same fetish in China. The expression 柳腰 liuyao traditionally expressed the Chinese ideal female figure: 'a waist like a willow tree'. Morohashi daikanwa jiten cites (Morohashi's Great Chinese-Japanese Dictionary) two examples for this expression. Both of them are from the Tang period (618-907). Apparently, the appraisal of a slender female figure in China is quite ancient. It appears that this Chinese term was introduced to Japan rather late. All the citations in The Great Shogakkan Dictionary of Japanese in which yanagigoshi appear is taken from the Shogunate period (including the one I have just cited). Thus, the term, taken from the Chinese vocabulary, possibly entered into circulation in Japan sometime in the seventeenth or the 18th century. The exact source is difficult to determine. The reference to a slender body of a beautiful woman is amply found in the Chinese literature that the Japanese 
literati of the Tokugawa period perused. For instance, in Pu Sungling's Strange Stories from a Chinese Studio, in the episode 'The Taoist Priest of Mt. Laoshan', the guest of the Priest summons a beauty who was none other than the Moon Goddess. She was 'slender (xian yao: having a slim waist) and elegant'. Akinari Ueda composed The Tales of Moonlight and Rain, inspired by Strange Stories from a Chinese Studio. The standard for a beautiful woman with a slim waist may have been introduced from China to Japan through such a channel (see Fig. 2 for an illustration for the episode 'The Taoist Priest of Mt. Laoshang'). The woman with the extreme slender figure in it reminds the Japanese readers of women described by Harunobu Suzuki.

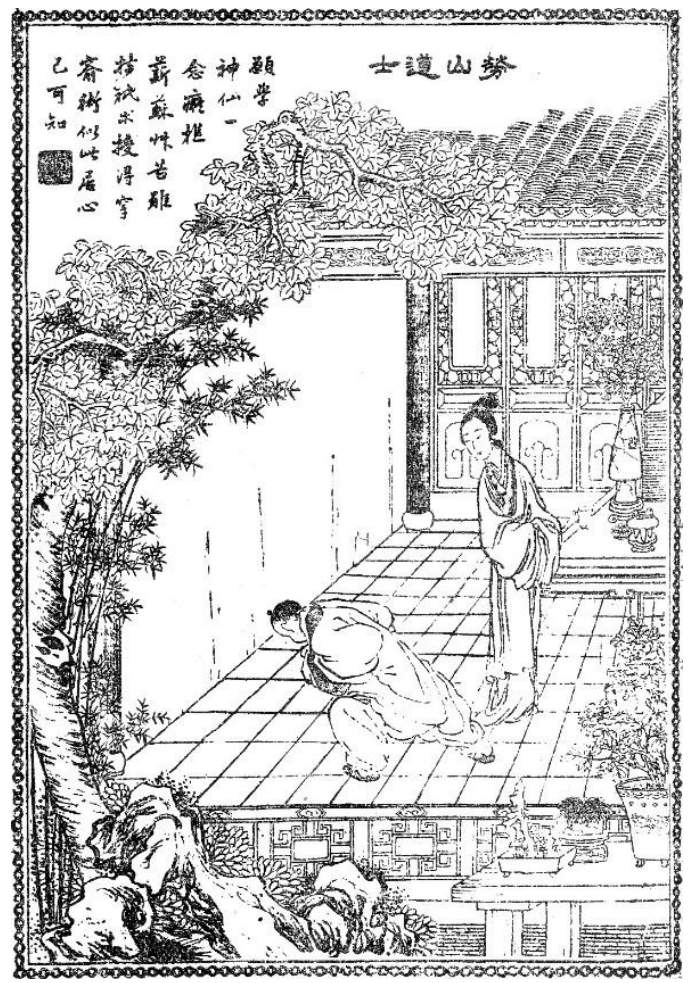

Fig. 2. 'The Taoist Priest of Mt. Laoshan', Chinese Tales from a Strange Studio.

We have outlined the trajectory of feminine physical beauty (of a slender body) in the medieval to early modern Japan and in the Chinese society of the Middle Ages. Now, then, what was (is) implied by the Russian standard of a 'good proportion'?

\section{New Take on the Body}

Let us examine the translated text of Three Trysts once again. As the title suggests, the hero meets a beautiful woman three times at three difference 
places by chance. For the first time he catches a bare glimpse of her at the window. He mostly (but barely) recognizes her facial features. (At this scene she is described as ada-na [stroinyi] as in Futabatei's translation which we examined.) For the second time he meets her in the woods. Here, too, Turgenev refers to her black eyes, black hair, beautiful neck, and so on, but not much to her bodily figure itself. (She is described as stroinyi once again, though.) At the third meeting at the ball, she is with "majectic line of her shoulders and arms and especial stateliness (velichavost') of her entire womanly figure.' Although we are not perfectly sure what is meant by 'stateliness' of a woman, surely it does not suggest slenderness. One is inclined to think that it rather refers to a glamorous shape.

This association may be partly justified by taking a look at the front cover of the present-day popular edition of Three Trysts (Fig. 3), where the heroine is described as a more or less glamorous woman with a protruded breast.

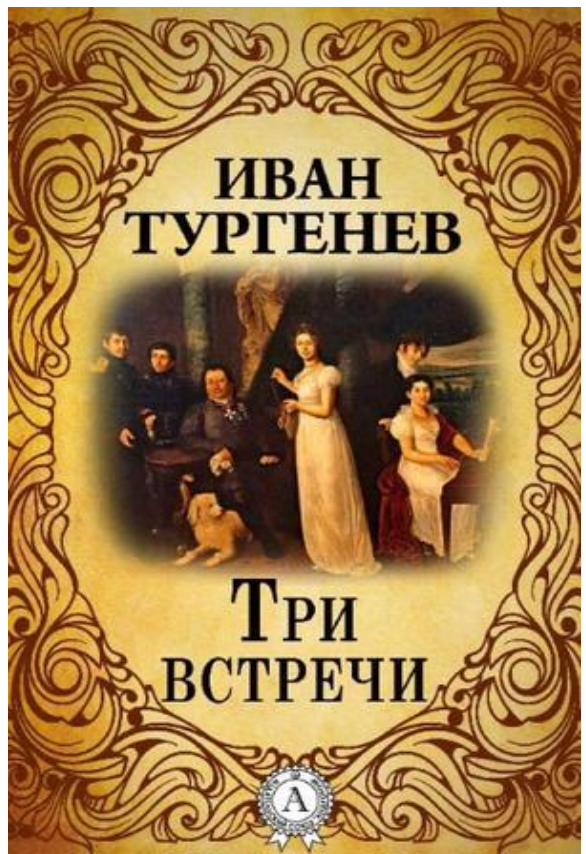

Fig. 3. Three Trysts. Moscow: Strebitsky, 2016.

This supposition is reinforced by taking a look at other works of Russian literature that Futabatei was well familiar with. For instance, in Anna Karenina, Lev Tolstoy describes a certain Sapho Stolz, beauty and star of the fashionable high society thus: 'In looking at her one wondered where, in that bolstered, wavy mass, her real, shapely (stroinaia [female form of stroinyi]) little body was hidden' (Tolstoy 1949, I: 292). That this 'shapeliness' 
involved a feminine glamorous body is revealed by the description in the same passage: 'Her head was a veritable scaffolding of false and natural hair of a delicate golden shade that made it seem in proportion to her full wellshaped bosom, very bare in front.' To render literally, 'shapely (stroino) protuberant breast, very open in the front' (Constance Garnett mistranslates stroinaia in this passage as 'slender', see Tolstoy 1926: 339). 'Shapeliness' foremost referred to a glamorous breast.

Although Anna Karenina herself is not described as stroinaia in the work, Tolstoy may have had such an image. At least, this can be sensed in the expectation of the readers.

Take Ivan Kramskii's well-known portrait of 'An Unknown Woman' as an example. Although the attribution of the 'unknown woman' to Anna Karenina is unfounded, at most, this painting is often considered as a representation of Anna and frequently used in the editions of Anna Karenina. As one can see, the 'unknown woman' is no skinny woman, but a rather pompous, even fluffy, glamorous woman. Such was, probably, an image of a beautiful and proportionate woman among the writers and the readers alike in the 19th century Russia.

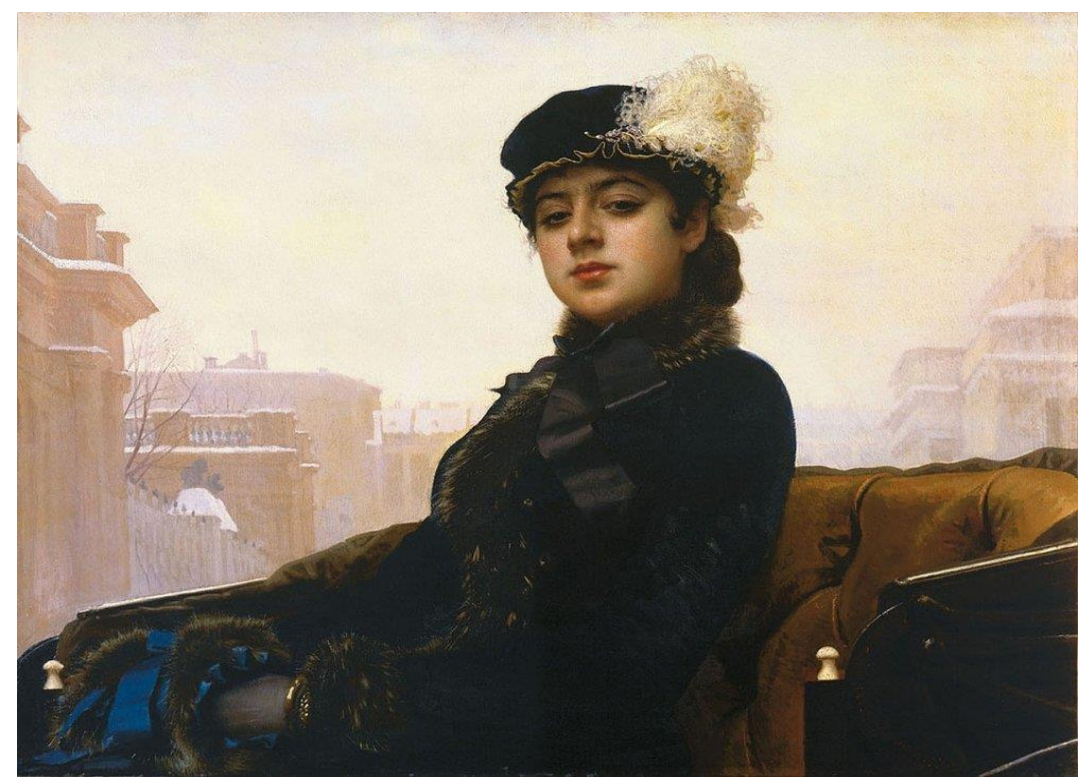

Fig. 3. Ivan Kramskii, 'Unknown woman'.

Futabatei, of course, did not know this. For Futabatei, a beautiful, proportionate female figure meant slimness. Thus, having rendered stroinyi as ada-na (sexy, erotic, chic) at the first tryst in Three Trysts, Futabatei translates the adjective stroinyi repeated in the original for the second and the third tryst as 'surari to shita (slender)', which was, obviously, a 
mistranslation. To exemplify, in the second 'tryst' with the lady in the woods, the hero admires her beauty, saying: 'How I looked into her eyes! How beautiful she was! Through the emerald green how attractively was her proportionate (stroinyi) figure brought to me!' Futabatei renders this as surari to shita. Ada-na for stroinyi was a mistranslation in this sense as well since $a d a-n a$ not only referred to sexiness (of a geisha), it also involved the admiration for a willowy figure (as described by Harunobu Suzuki). The notions of taoyaka and nayoyaka (both meaning 'graceful'), referred to in the definition of ada-na in the Shogakkan Japanese Dictionary conveyed the sense of being svelte as well.

It is interesting, though, to find that the aesthetic standard in Russia may be changing in the contemporary society. If the 19 th century ideal of a female figure as glamorous is changing, it is also significant to note that the 19 th century ideal of a male figure was, probably, different from that of a woman. In Anna Karenina, where we have examined the meaning of stroinyi vis-à-vis Lady Stolz, there are a few more instances of stroinyi applied to men. Anna sees her son and thinks 'he was charming, with his fair curls, blue eyes, and sturdy (stroinymi) legs in neatly fitting stockings' (Tolstoy 1949, I: 105). If a good proportion in a female figure meant glamorousness, it meant, for men, 'sturdiness', 'muscularity', 'firmness', etc. Whereas the present-day Russian dictionaries continue to define stroinyi as 'having a good proportion', the exact meaning-content of it may be partly changing from being 'glamorous' to being 'slender'. (For instance, the most standard contemporary Russian dictionary by Ozhegov defines stroinyi as 'of beautiful and proper proportion'.) Although the basic admiration for a glamorous female body is still persistent, there seems to be an emergent new sensibility for the appreciation of a skinnier figure.

As if to endorse this change, some Russian-English Dictionaries are adding the sense of 'svelte' to that of 'proportionate' in the translation of stroinyi (the 1980 Edition of the Oxford Russian-English Dictionary is one of them). As pointed out earlier, Garnett tends to 'mistranslate' stroinyi into 'slender'. She may have been too sensitive to the shift of the meaning of stroinyi from 'glamorous' to 'slender'. Some Russian-Japanese Dictionaries follow suit by adding 'surari to shita (slender)' to the translation (Kenkyusha's Russian-Japanese Dictionary, Iwanami shoten’s Russian-Japanese Dictionary, and so forth; Kenkyusha's Dictionary even lists 'slender' as the first meaning of stroinyi).

What has caused this change in the lexicography of the Russian language is unclear. Traditionally, the Russian society valorized plumpness as a sign of good health. (The valorization of puffy women is, probably, the extension of this idea.) The Russian word khudoi is still used both in the 
sense of 'bad' and in that of 'lean, skinny'. Then what has caused the new consciousness of valorizing slenderness in a female figure in Russia?

One interesting hypothesis is proposed by Yuri Kato. She argues, analyzing a few contemporary Russian films (Piter FM, 2006 and On Love, 2015), in her article 'A Change in Women's Features in Russian Literature and Films: From "Maturity" to "Kawaii"" that under the influence of the popularity of Japanese anime in Russia a new sensibility of preferring a cute, immature, underdeveloped (kawaii) girl to a mature woman. Her argument centers on the shift of a value from maturity to cuteness/childishness, this, obviously entails a new standard of a slender feminine physical beauty as opposed to the 'proportionate' glamorous body of women of the past: 'a man can prefer a glamorous body of an elder [mature] woman to a slender figure [of a girl]' (chap 3-2, n.p.). Of course, the extent of influence of the Japanese anime on the wide cultural scene in Russia has to be measured carefully. In the context of the present paper, the intrusion of this new outlook on the female (physical) beauty in literature has to be verified in the wider discursive space, which remains my subsequent research agendum.

In contrast, in Japan, where, as we have seen, the inclination for female svelteness has been centuries-long tradition, it has been sharpened in the past several decades. It was symbolized by the idolization of the British model 'Twiggy' in the 1960s. It is well-known that this new emphasis on female skinniness became a major social problem in the United States where many young girls and women suffered from anorexia in their desperate desire to lose weight and be skinny. The tragic death of Karen Carpenter symbolized this problematic obsession as will be mentioned below.

Twiggy, or Dame Lesley Lawson, is a British fashion model and actress, born in 1949. She acclaimed fame not only in Britain but also worldwide by the mid-1960s. She visited Japan and created sensation, subsequently appearing in a number of TV commercials. She was extremely skinny, weighing only $41 \mathrm{~kg}$ (her height was $165 \mathrm{~cm}$ ) and a twig-like proportion came to be idolized in Japan.

The new fad for female skinniness was a global phenomenon. In the United States, it was represented by the popular singer Karen Carpenter (1950-83). She started dieting already at high school. She weighed mere $54.4 \mathrm{~kg}$ at the height of her musical career. By 1975 her weight was mere $41.3 \mathrm{~kg}$. And in 1983 she was already too weak to survive (https://www.smoothradio.com/artists/carpenters/karen-carpenter-deathstory-solo-album-husband/).

It is not clear whether Karen Carpenter's anorexia was triggered by the new standard of skinny beauty propagated by Twiggy. Whatever the case, 
Karen Carpenter did symbolize the advent of a feminine ideal figure which had not been recognized in the Western cultures, at least in the last few centuries.

Once again whether Twiggy or Karen Carpenter or any one representative of culture can explain away the change completely or not is dubious. The influence, probably, mutual. The new social trend for female slenderness produced a cultural icon such as Twiggy. Twiggy in turn perpetuates and represents the new value.

\section{Conclusion}

Probably, the same can be said about the literary texts. In the 19th century, when the Japanese culture seriously started encounter with the Western civilization, it was not familiar with the ideal of female (bodily) glamour. On the contrary, it valorized feminine slenderness. In spite of the huge rush of Euro-American cultural discourse into modernizing Japan, it appears it remained more or less indifferent to the glamorous body of a woman. This remaining tradition is now, apparently, taking hold in the Japanese society typically expressed in popular such as animation and comics. Ironically, it is exerting revert influence on the Western cultures, which is observed in the contemporary Russian sub-culture. Literary/cultural discourse reflects the value system of the culture, but it also determines it. Thus we observe the interplay of the standard of physical beauty and the texts representing it and represented by it through translation; that is to say, the translation between various media: literature, film, anime, fashion, and so on and on.

\section{Bibliography}

Dal' V (1934) Tolkovyi slovar' zhivogo velikorusskogo iazyka. Reprint. Tokyo: Tachibana shoten.

Furukawa T (1920) Rowa jii. Tokyo: Maruzen.

Futabatei S (1971) Meguriai. Futabatei Shimei zenshū. Meiji bungaku zenshū, volume 17. Tokyo: Chikuma shobō.

Kato Y (2019) A Change in Women's Features in Russian Literature and Films: From 'Maturity' to 'Kawaii'. In Yokota-Murakami T and Hiraishi N (eds) Japanese Pop-texts in the Global Context. Leiden: Brill.

The Monthly Bulletin of the Hitotsubashi University Library. Special Issue. Katalog russkim knigam kuplennym do 1902 goda vkliuchitel'no (Catalogue of Russian Books Purchased up to the Year 1902) (1959).

Murasaki S (1925) The Tale of Genji [translated by Arthur Waley]. London: Allen \& Unwin.

Pu S (2003) Strange Stories from a Chinese Studio. Translated by Herbert A. Giles. Honolulu: UP of the Pacific. 
Sakado Y (ed) (1930) Suzuki Harunobu. Ukiyo-e taika shūsei, volume 5. Tokyo: Taihōkaku.

Reif F (1866) Novye parallel'nye slovar' iazykov russkogo, frantsuzckogo, nemetskogo, i angliiskogo v tsetyrekh tomakh. Third Edition. St. Petersburg: Fel'ten.

Tolstoy LN (1949) Anna Karenina, volume 1 [translated by Rochelle S. Townsend]. London: Dent.

Tolstoy LN (1926) Anna Karenina [translated by Constance Garnett]. London: Heineman.

Turgenev IS (1963) Tri vstrechi. Polnoe sobranie sochnenii I pisem. Moscow: Izdatel'stvo Akademii Nauk SSSR.

Venuti L (1955) The Invisibility of a Tranlator: A History of Translation. London: Routledge.

Yokota-Murakami T (2016) Futabatei Shimei: Kutabatte shimae. Kyoto: Minerva shobō.

(2011) The Creation of 'A Lady': Gender and Sexual Politics in the Earliest Japanese Translations of Walter Scott and Charlotte Brontë. In Larkosh C (ed) Re-engendering Translation: Transcultural Practice, Gender/Sexuality and the Politics of Alterity. Manchester: St. Jerome, pp. 91-110. and Hiraishi N (eds) (2019) Japanese Pop-Culture in the Global Context. Leiden: Brill. 